\title{
A surprising extension of the preconditioned stimulus beyond the cotermination of the US and the added element does not alleviate blocking to the added element
}

\author{
JOHN J. B. AYRES and JOAN C. BOMBACE \\ University of Massachusetts, Amherst, Massachusetts
}

\begin{abstract}
Rats were subjected to the Kamin two-stage blocking procedure. First, a stimulus, A, was conditioned and then reinforced in compound with a target stimulus, B. During compound training, an attempt was made to alleviate blocking of conditioning to B by presenting a "surprise" stimulus for 5 sec following the reinforced $A B$ compound. The surprise stimulus consisted of the continued presentation of the previously reinforced element, A. During A training, A had never extended beyond the moment of reinforcement; thus, its extension beyond reinforcement during AB training was hypothesized to be "surprising" and, therefore, expected to alleviate blocking. Blocking in this condition was, however, just as strong as in a standard blocking condition. The results do not favor a surprise interpretation of unblocking but do seem to be consistent with other theoretical views (e.g., Rescorla \& Wagner, 1972).
\end{abstract}

In recent years, evidence has accumulated that stresses the importance of "surprise" in Pavlovian conditioning. Kamin $(1968,1969)$ showed that when a target stimulus, $B$, was reinforced in compound with another stimulus, $A$, conditioning to $B$ was "blocked" if A had itself been conditioned previously. In contrast, conditioning to B was not blocked if $\mathbf{A}$ was novel. Kamin suggested that blocking occurred when the US was not surprising. The US should not be surprising on $A B$ trials if the US were well predicted by $A$. Kamin further suggested that when the US was surprising, it evoked a kind of "backward scanning" in which the subject would mentally connect those events that had just preceded the surprising US with the US itself. It was this backward scanning, then, that was ultimately necessary for conditioning.

Additional evidence for this point of view was adduced first by Kamin and then by others. Kamin $(1968,1969)$ found, for example, that if the US intensity were increased between $A$ training and $A B$ training (or if during $A B$ training, a second, unexpected, presentation of the US occurred $5 \mathrm{sec}$ after the first), blocking to $\mathrm{B}$ would be alleviated. This happened, presumably, because the new US intensity (or the added US) was surprising. Similarly, Dickinson, Hall, and Mackintosh (1976) found that if A pre-

This research was supported by Grant MH 28226-01 from the National Institute of Mental Health and by Biomedical Sciences Support Grant RR 07048 to the University of Massachusetts. Address correspondence to J. J. B. Ayres, Department of Psychology, Middlesex House, University of Massachusetts, Amherst, Massachusetts 01003 dicted two USs and $\mathrm{AB}$ predicted only one, blocking was again alleviated, and again, presumably, because the change in the US presentation from $A$ to $A B$ training was surprising. Finally, Gray and Appignanesi (1973) found that if an innocuous surprise event, such as a .3-sec "flash" of the AB compound, followed the US during AB training, this, too, alleviated blocking. Furthermore, the amount of alleviation depended upon the time interval between the termination of the US and the onset of the surprise stimulus. Alleviation was maximal when the interval was $3 \mathrm{sec}$, less when it was $5 \mathrm{sec}$, and essentially absent when it was $10 \mathrm{sec}$. Like Kamin, Gray and Appignanesi attributed their unblocking effect to the backward scanning evoked by the surprise event. The decline in unblocking that occurred when the interval between US termination and the surprise event was increased also seemed reasonable from this view: It could have been due to the fading of the stimulus traces to be scanned (and associated during the post-US interval) or to the declining ability of the scanning mechanism to scan backwards over increasingly longer periods of time.

There are, however, interpretive problems associated with the Gray and Appignanesi findings. One problem is that there was no control group that received the surprise event during $A$ training and was thus "prepared" for it during AB training. Had such a control group also shown unblocking, then an interpretation in terms of surprise would surely have been questionable. A more serious challenge to the surprise interpretation, however, has recently been provided by Donegan, Whitlow, and Wagner (1977). In an extensive series of studies, these authors failed 
to replicate the surprise result obtained by Gray and Appignanesi.

A more general problem in the literature on surprise is the definition of the surprise construct itself. The problem is to define surprise independently of the phenomenon it is invoked to explain. That is to say, if surprise is to explain unblocking, then one must have some way of ascertaining whether a manipulation is surprising other than looking to see whether it causes unblocking. Fortunately, Dickinson and Mackintosh (1979) have recently offered a definition that may meet the requirement. They suggest that " $[t]$ he occurrence of a surprising event is ... not related to any absolute property of a stimulus but to the fact that the presentation or omission of a stimulus is at variance with the animal's previous experience"' (p. 163).

The present study uses a manipulation that fits the definition of Dickinson and Mackintosh (1979) and is related to, but slightly different from, the manipulations of Gray and Appignanesi (1973) and Donegan et al. (1977). In our procedure, a surprise "flash" was not given after US termination. Instead, on $A B$ trials, the conditioned A cue was allowed for the first time to persist 5 sec beyond US termination.

As in the previous studies cited, the present study paired auditory and visual CSs with electric grid shock USs while rats were barpressing for food. Suppression in the barpress rate during CS trials was taken as an index of conditioning.

\section{METHOD}

\section{Subjects}

Forty male albino Sprague-Dawley rats, 85-90 days old when obtained from the Holtzman Company (Madison, Wis.), were housed individually in a continuously lighted room and were kept at $80 \%$ of their free-feeding body weights.

\begin{abstract}
Apparatus
Eight Gerbrands Skinner boxes with grid floors, centrally mounted levers, and left-side dipper feeders were housed in ventilated .61-m cubes of $12.7-\mathrm{mm}$ plywood lined with acoustical tile. On the clear plastic lid of each box were two $10-\mathrm{cm}$-diam speakers. One provided an intermittent (1 sec on, $.11 \mathrm{sec}$ off) white noise CS of $80-\mathrm{dB}$ intensity re $20 \mu \mathrm{N} / \mathrm{m}^{2}$; the other was not used. A second CS was provided by turning on a $28-\mathrm{V}$ cue light mounted over the dipper opening $95 \mathrm{~mm}$ above the grid floor and a second $28-\mathrm{V}$ lamp mounted on the chamber lid. When these lights were off, the boxes were totally dark. The US was scrambled grid shock $(1 \mathrm{~mA}$ for $1 \mathrm{sec}$ ) provided by eight Grason-Stadler shock sources (Models E1064GS and 700). Barpressing, the baseline response to be suppressed by CS trials, was reinforced with $4-\sec$ presentations of a .1 -ml dipper cup containing a $32 \%$ (by weight) sucrose solution.
\end{abstract}

\section{Procedure}

Preliminary barpress training began with three daily sessions of barpress shaping and ended with five daily 1-h sessions under a VI 1-min schedule of reinforcement.

The 40 rats were then assigned randomly to five groups of eight. All groups received seven daily 1-h sessions. Groups Block and Surprise received in each session four presentations of the intermittent noise CS. Each presentation was $120 \mathrm{sec}$ in duration and coterminated with a 1-sec 1-mA scrambled grid shock US. For Group Prepared, each of the four noise CS presentations was 125 $\mathrm{sec}$ in duration and terminated $5 \mathrm{sec}$ after the shock US. For all three groups, the CS-US pairings occurred while the rats barpressed for sucrose on a VI 1-min schedule. For Groups Block Control and Surprise Control, no CSs or USs were presented during this phase. These two groups merely continued to barpress on the VI schedule.

In each of two daily 50 -min sessions, all five groups received three reinforced presentations of a compound stimulus consisting of the intermittent white noise (Stimulus A) together with the light CS (Stimulus B). For all groups, the light was $120 \mathrm{sec}$ in duration and coterminated with the 1-sec 1-mA grid shock US. For Groups Block and Block Control, the noise was also $120 \mathrm{sec}$ in duration and coterminated with the light and shock. For Groups Surprise, Surprise Control, and Prepared, however, the noise was $125 \mathrm{sec}$ in duration and continued for $5 \mathrm{sec}$ beyond the termination of the light and shock.

On the day following the last $\mathrm{AB}$-training session, there was a single 1-h session in which the rats were permitted to barpress on the VI 1-min schedule in the absence of CSs or shock USs. This session permitted baseline response rates, depressed by shock in the previous phases, to recover so that suppression to the CS could be detected reliably in the next phase.

A savings test for conditioning to the target, light CS, Stimulus $B$, began on the day following the recovery session. Testing consisted of two daily 50 -min sessions, each with four 2 -min light trials presented while the rats barpressed for sucrose on the VI schedule. Of this total of eight test trials, Trials 2, 4, 5, and 7 terminated with the onset of a $1-\mathrm{sec} 1-\mathrm{mA}$ shock. Only half, rather than all, of the eight trials were reinforced so as to slow down conditioning and thereby prolong the expected separation among groups. Following the savings tests, there were 2 days of extinction tests for conditioning to Stimulus A. These tests were identical to the savings tests except that the intermittent noise, Stimulus A, replaced the light, Stimulus B, and all USs were omitted.

Suppression to all CSs was indexed in terms of the Annau and Kamin (1961) suppression ratio, D/(D+B), where D denotes the response rate during the $\mathrm{CS}$ and $\mathrm{B}$ denotes the rate in a 2-min period just before the CS. With this ratio, a score of zero denotes strong conditioned suppression, while a score of .5 suggests no effect.

\section{RESULTS}

Suppression to the noise, Stimulus A, was rapidly acquired by all three groups that received CS-US pairings. Over the last 3 days of training, mean suppression ratios were $.15, .09$, and .08 for Groups Block, Surprise, and Prepared, respectively. These values did not differ reliably $(\mathrm{H}=3.26, \mathrm{p}>.10)$.

On the first trial of $\mathrm{AB}$ training, the unconditioned effects of the novel noise + light compound were very large, so large that groups for which both elements were novel suppressed as much as did those for which the noise element had been preconditioned. Mean suppression ratios were $.13, .04, .08, .04$, and .06 for Groups Block, Block Control, Surprise, Surprise Control, and Prepared, respectively. Differences among groups were not reliable $(H=5.98$, $\mathrm{p}=.20$ ).

Figure 1 shows the results of the savings test for conditioning to the target, light CS, Stimulus B. Clearly, all three groups for which Stimulus A had been preconditioned showed evidence of blocking. A 


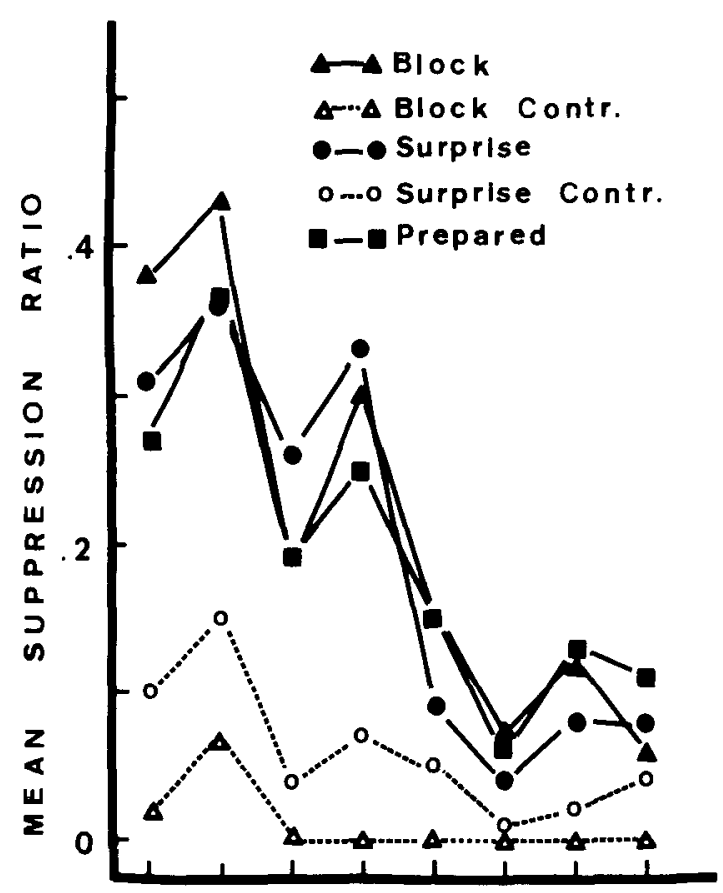

T R I A L S

Figure 1. Group mean suppression ratios during savings tests for conditioning to Stimulus B.

Kruskal-Wallis analysis of variance on the data from the first test day showed that differences among groups were reliable $(\mathrm{H}=22.52, \mathrm{p}<.001)$; a priori Wilcoxon rank sums contrasts indicated that Groups Surprise and Prepared each suppressed less than Group Surprise Control and that Group Block suppressed less than Group Block Control (Ts $<44$, ps $<.01)$. Differences among the three preconditioned groups were not reliable $(\mathrm{H}=1.04, \mathrm{p}=.60)$, nor was the difference between the two control groups $(T=54.5, \mathrm{p}>.10)$.

During the first test day for conditioning to the target, light CS, median pre-CS rates of Groups Block, Block Control, Surprise, Surprise Control, and Prepared, respectively, were $22,15,25,22$, and 18 responses per min. These values did not differ reliably $(\mathrm{H}=7.61, \mathrm{p}=.10)$. Thus, differences in suppression among groups were not complicated by differences in baseline rates.

Figure 2 shows the results of the extinction test for conditioning to the noise, Stimulus $A$. The breaks in the plots separate the 2 days of extinction testing. These data were collected to answer two questions. First, did the 5-sec extension of Stimulus A past the moment of reinforcement weaken conditioning to A (cf. Barnes, 1956; Burkhardt \& Ayres, 1978; Mowrer \& Lamoreaux, 1942, Schneiderman, 1966)? Second, did A produce more suppression in the three experimental groups for which it had been preconditioned than in the two control groups for which it had not?
Since Figure 2 suggests that differences among groups were similar on the 2 days of extinction testing, statistical analyses were performed on mean suppression ratios averaged over all eight trials. Group mean ratios were $.32, .25, .39, .34$, and .31 for Groups Block, Block Control, Surprise, Surprise Control, and Prepared, respectively. A KruskalWallis analysis of variance performed on the mean suppression ratios for all eight trials for each rat failed to reveal any differences among groups $(\mathrm{H}=$ $5.17, \mathrm{p}>.20$ ). Nevertheless, a priori tests were conducted to answer the specific questions raised above. With regard to the first question, these tests showed that neither Group Surprise nor Group Prepared suppressed less than Group Block (Ts $<76$, ps $>.10$ ). Similarly, Group Surprise Control did not suppress less than Group Block Control $(T=81, p>.10)$. Also, Groups Surprise, Surprise Control, and Prepared combined did not suppress less than Groups Block and Block Control combined $(\mathrm{T}=305, \mathrm{p}>$ .10). Thus, there was no evidence that extending A 5 sec past the moment of reinforcement significantly weakened its associative strength. With regard to the second question, a comparison of Groups Block, Surprise, and Prepared combined vs. Groups Block Control and Surprise Control combined also failed to produce a reliable difference $(T=304, p>.10)$. Thus, there was no evidence that the groups for which Stimulus A had been pretreated differed from those for which it had not.

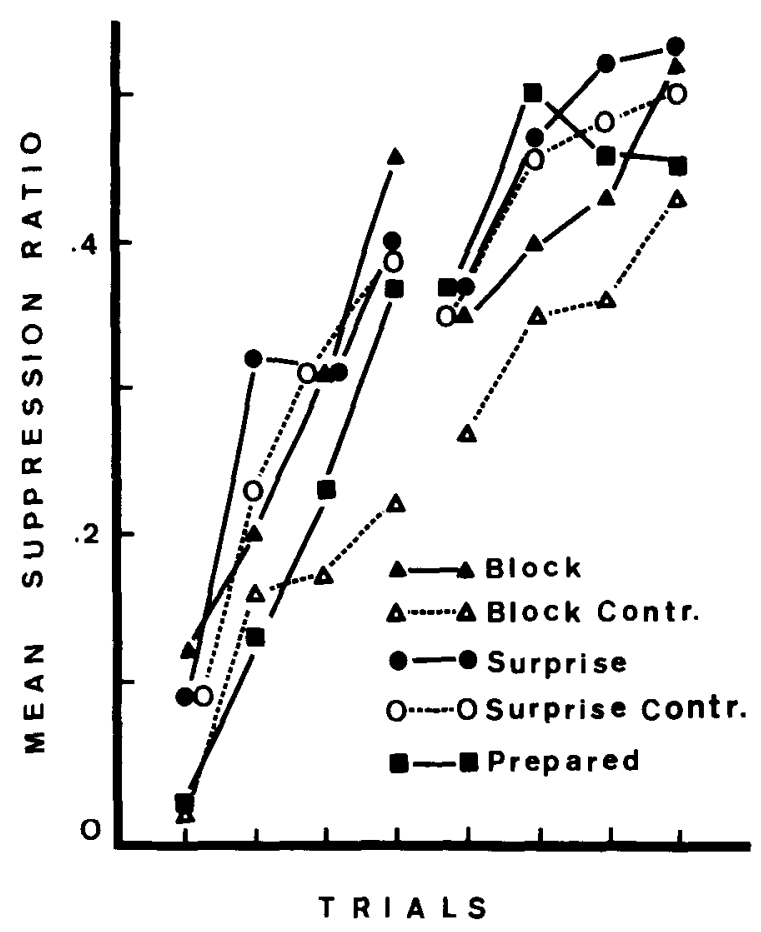

Figure 2. Group mean suppression ratios during extinction tests for conditioning to Stimulus $A$. 
Over the 2 days of extinction testing, the median pre-CS rates for Groups Block, Block Control, Surprise, Surprise Control, and Prepared, respectively, were $21,21,25,21$, and 19 responses per min. These values did not differ reliably $(\mathrm{H}=2.53, \mathrm{p}>.60)$.

\section{DISCUSSION}

The main finding of this study was that when an event incongruent with the subjects' past experience occurred shortly after a reinforced $\mathbf{A B}$ trial, unblocking was not produced. If one accepts the definition of surprise proposed by Dickinson and Mackintosh (1979), then the theoretical meaning of this finding is clear; surprise is not sufficient for unblocking (cf. Donegan et al., 1977; Kohler \& Ayres, 1979; Maleske \& Frey, 1979; Gaioni, Note 1).

There is a sense, however, in which even the findings of Dickinson and Mackintosh (1979) support this same conclusion. They found that the surprising posttrial event must be "reinforcer-specific" in order to produce unblocking. For example, in their research, Stimulus A terminated with the onset of a shock, and then this pairing was followed $8 \mathrm{sec}$ later by a posttrial shock. In the next phase, the $A B$ compound ended in the onset of a shock, but the posttrial shock was omitted. Under these conditions, unblocking occurred. This case was one in which the stimulus that was omitted was similar to the one used to reinforce conditioning to the CSs, and thus it serves as an example of reinforcer-specific surprise. In another condition, Stimulus A terminated in the onset of shock, and then this pairing was followed by posttrial delivery of food. In the next phase, the AB compound terminated in the onset of shock, but the posttrial delivery of food was omitted. Under this condition, unblocking did not occur. This case was one in which the stimulus that was omitted was not similar to the one used to reinforce conditioning to the CS, and thus it serves as an example of a surprise event that was not reinforcer-specific. From this example, we see that it is not sufficient for a posttrial event to be surprising in order to produce unblocking; the event must not only be surprising, it must also be reinforcer-specific.

But what exactly is meant by the concept of reinforcer-specific surprise? Presumably, it refers to a surprising change in, a surprising presentation of, or a surprising omission of a stimulus similar to the US used to reinforce conditioning to Stimuli A and B in the blocking paradigm. Kamin's $(1968,1969)$ increase in US intensity between $A$ training and $A B$ training qualifies, as does his surprising presentation of an extra posttrial US (Kamin, 1968, 1969). The omission of an expected posttrial US also qualifies (Dickinson et al., 1976; Dickinson \& Mackintosh, 1979). All of these manipulations have been shown to produce unblocking. But what about a change in the temporal location of the US relative to the time of CS onset? If this parameter is changed between $A$ and $\mathrm{AB}$ training, is this not an instance of reinforcerspecific surprise? Gaioni (Note 1), Kohler and Ayres (1979), and Maleske and Frey (1979) all used a fixed CS-US interval during $A$ training and then changed that interval during $\mathrm{AB}$ training. For example, in the study by Kohler and Ayres (1979), the CS-US interval during $\mathrm{A}$ training for one group was always $120 \mathrm{sec}$, but during $\mathrm{AB}$ training that interval varied between 17 and $220 \mathrm{sec}$ from trial to trial. This manipulation and the similar manipulations of Gaioni (Note 1) and Maleske and Frey (1979) did not produce any evidence of unblocking.

Was the surprise stimulus that produced unblocking for Gray and Appignanesi (1973) an example of reinforcer-specific surprise? Recall that it consisted of a brief "flash" of the AB compound after the reinforced $A B$ trial. Because of this, Dickinson and Mackintosh (1979) suggested that "the posttrial stimulus in the Gray and Appignanesi study was likely to have been a conditioned aversive stimulus [and that] their results suggest that it is necessary for the posttrial stimulus to be similar to the reinforcer only in motivational significance in order to be effective" (p. 175). However, Gray and Appignanesi themselves explicitly denied this possibility, saying "it does not seem appropriate to consider the surprise stimulus as a representation of the CS as such, because the characteristics of the briefly presented stimuli appear to be quite different from the long-duration CS. The white noise when presented so briefly becomes a dulled click, and the light a mere wink" (1973, p. 379). In contrast, the surprise stimulus used in the present research was $5 \mathrm{sec}$ in duration, presumably long enough to be recognized as the preconditioned A stimuius. Thus, there is more reason to claim reinforcer-specific surprise in the present research than in that of Gray and Appignanesi. Needless to say, the surprise stimulus used here did not produce unblocking.

Based on this survey, we find that, for us at least, the general concept of surprise and the more precise concept of reinforcer-specific surprise are simply not helpful in organizing the literature on unblocking. Adherents of the surprise view may take offense at this conclusion. They might observe (and correctly so) that there was no evidence in the studies that failed to produce unblocking that the subject was "really" surprised by the manipulation. By the same token, in the studies that succeeded in producing unblocking, there was also no evidence of surprise other than the unblocking that the surprise construct was invoked to explain. Given this state of affairs, it is easy to explain both the successes and failures using the surprise notion. The question is: Has the surprise idea been successful in predicting the successes and failures? We believe that it has not. 
We turn now to the extinction tests for conditioning to Stimulus $\mathbf{A}$ that followed the savings tests for conditioning to Stimulus B. We conducted these tests with the Rescorla and Wagner (1972) model in mind. According to that model, the amount of conditioning that accrues to a stimulus, $\mathrm{B}$, on a reinforced trial is proportional to the discrepancy between the current conditioned strength of the compound containing $B$ and the maximum level of conditioning the US in use will support. More formally, it is proportional to $\alpha_{B} \beta(\lambda-\bar{V})$. Here, $\alpha_{B}$ and $\beta$ are values between 0 and 1; $\alpha_{B}$ increases with the salience of $B$, and $\beta$ with the US intensity; $\lambda$ represents the asymptotic level of conditioning that the US will support; and $\bar{V}$ represents the sum of the conditioned strengths of the target element, B, and all other stimuli present at the moment of reinforcement. According to the model, blocking occurs because, after pretreatment, the $A$ cue is highly conditioned so that $V_{A}$ and, hence, $\bar{V}$ approximate $\lambda$. Unblocking, in contrast, is produced by any manipulation that increases the $\lambda-\bar{V}$ discrepancy. One such manipulation is the extinction of the conditioned strength of the A cue following pretreatment. This possibility motivated us to ask whether the extension of A $5 \mathrm{sec}$ past the moment of reinforcement during $\mathbf{A X}$ training so weakened the conditioned value of $A$ that unblocking might have been expected. As noted above, suppression to the A cue in the A extinction tests did not support this possibility; thus, the model predicts blocking in Group Surprise, which is what we found.

We were also interested in an obvious prediction the model makes about the conditioned strength of Stimulus $\mathrm{A}$ following $\mathrm{AB}$ training. The model predicts that, following $A B$ training, groups for which the A cue was preconditioned (Groups Block, Surprise, and Prepared) should suppress more to Stimulus $\mathbf{A}$ than should the groups for which the A cue was not preconditioned (Groups Block Control and Surprise Control). In fact, assuming Stimuli A and B to be of equal salience, the model predicts that $A$ should be roughly twice as excitatory for the pretreated groups as for the nonpretreated groups. For the pretreated groups, $V_{A}$ approximates $\lambda$ at the start of $A B$ training and at the end. For the nonpretreated groups, $V_{A}$ and $V_{B}$ approximate zero at the start of $\mathrm{AB}$ training, and each approximates $\lambda / 2$ at the end. One should note, however, that, as the salience of $A$ increases relative to that of $B, V_{A}$ increasingly approximates $\lambda$ at the end of $A B$ training, even for the nonpretreated groups.

Previous data from our laboratory suggest that $A$, the intermittent noise, is considerably more salient than the light, Stimulus B. Thus, our procedure was not one that would theoretically maximize differences between pretreated and nonpretreated groups in terms of the excitation conditioned to A. Consis- tent with the salience hypothesis, Bombace (Note 2), using tone and light CSs, has obtained the predicted difference between pretreated and nonpretreated groups, at least on the first A-test trial. We believe that, in our laboratory, tone and light are more similar in salience than are noise and light. Other evidence consistent with the salience hypothesis has been described by Marchant and Moore (1973). Still, in an extensive series of studies using trace conditioning procedures, Kohler (1979) found no differences between pretreated and nonpretreated groups in the suppression to $A$. This was true whether extinction tests to A followed or preceded savings tests to B. It was also true whether A was tone and B was light or vice versa. Similarly, Cheatle and Rudy (1978) and vom Saal and Jenkins (1970, Experiment 1) found no difference between pretreated and nonpretreated groups in responding to $\mathrm{A}$. Because of the potential theoretical significance of these findings, it is unfortunate that $\mathbf{A}$ testing has not been a routine procedure in investigations of blocking. Given the contradictory nature of the available data, it is clear that systematic investigations of the associative strength of $A$ at the conclusion of the blocking paradigm are sorely needed.

\section{REFERENCE NOTES}

1. Gaioni, S. J. Blocking and temporal predictability. Paper presented at the meeting of the Eastern Psychological Association, New York, 1975.

2. Bombace, J. C. CS pre-exposure retards conditioning to $A$ but does not alleviate blocking to $X$. Manuscript in preparation, 1979.

\section{REFERENCES}

Annau, Z., \& Kamin, L. J. The conditioned emotional response as a function of intensity of the US. Journal of Comparative and Physiological Psychology, 1961, 54, 428-432.

Barnes, G. W. Conditioned stimulus intensity and temporal factors in spaced-trial classical conditioning. Journal of Experimental Psychology, 1956, 51, 192-198.

Burkhardt, P. E., \& Ayres, J. J. B. CS and US duration effects in one-trial simultaneous fear conditioning as assessed by conditioned suppression of licking in rats. Animal Learning \& Behavior, 1978, 6, 225-230.

Cheatle, M. D., \& Rudy, J. W. Analysis of second-order odoraversion conditioning in neonatal rats: Implications for Kamin's blocking effect. Journal of Experimental Psychology: Animal Behavior Processes, 1978, 4, 237-249.

Dickinson, A., Hall, G., \& Mackintosh, N. J. Surprise and the attenuation of blocking. Journal of Experimental Psychology: Animal Behavior Processes, 1976, 2, 313-322.

Dickinson, A., \& Mackintosh, N. J. Reinforcer specificity in the enhancement of conditioning by posttrial surprise. Journal of Experimental Psychology: Animal Behavior Processes, 1979, 5, 162-177.

Donegan, N. H., Whitlow, J. W., JR., \& Wagne R, A. R. Posttrial reinstatement of the CS in Pavlovian conditioning: Facilitation or impairment of acquisition as a function of individual differences in responsiveness to the CS. Journal of Experimental Psychology: Animal Behavior Processes, 1977, 3, 357-376. 
Gray, T., \& Appignanesi, A. A. Compound conditioning: Elimination of the blocking effect. Learning and Motivation, $1973,4,374-380$.

KAMIN, L. J. "Attention-like" processes in classical conditioning. In M. R. Jones (Ed.), Miami Symposium on the Prediction of Behavior, 1967: Aversive Stimulation. Coral Gables, Fla: University of Miami Press, 1968.

Kamin, L. J. Predictability, surprise, attention and conditioning. In B. A. Campbell \& R. M. Church (Eds.), Punishment and aversive behavior. New York: Appleton-Century, 1969.

KoHLER, E. A. Serial compounds and trace conditioning procedures in the Kamin blocking paradigm. Unpublished doctoral dissertation, University of Massachusetts-Amherst, 1979.

Kohler, E. A., \& Ayres, J. J. B. The Kamin blocking effect with variable-duration CSs. Animal Learning \& Behavior, 1979, 7, 347-350.

Maleske, R. T., \& Frey, P. W. Blocking in eyelid conditioning: Effect of changing the CS-US interval and introducing an intertrial stimulus. Animal Learning \& Behavior, 1979, 7, 452-456.

Marchant, H. G., III, \& Moore, J. W. Blocking of the rabbit's conditioned nictitating membrane response in Kamin's two-stage paradigm. Journal of Experimental Psychology, 1973, 101, $155-158$.

Mowrer, O. H., \& Lamoreaux, R. R. Avoidance conditioning and signal duration-A study of secondary motivation and reward. Psychological Monographs, 1942, 54(5, Whole No. 247). Rescorla, R. A., \& Wagner, A. R. A theory of Pavlovian conditioning: Variations in the effectiveness of reinforcement and nonreinforcement. In A. H. Black \& W. F. Prokasy (Eds.), Classical conditioning II: Current research and theory. New York: Appleton-Century, 1972.

Schneiderman, N. Interstimulus interval function of the nictitating membrane response of the rabbit under delay versus trace conditioning. Journal of Comparative and Physiological Psychology, 1966, 62, 397-402.

vom SaAL, W., \& Jenkins, H. M. Blocking the development of stimulus control. Learning and Motivation, 1970, 1, 52-64.

\section{NOTES}

1. The session lengths were reduced from 60 to $50 \mathrm{~min}$ and the number of trials from four to three during $A B$ training to permit comparisons with other experiments that were being conducted in the laboratory and for which these changes were required.

(Manuscript received August 19, 1981; revision accepted for publication January 12, 1982.) 